\title{
Physical Activities of Students During Lockdown: An Exploratory Survey
}

\author{
Shefali Pandya ${ }^{1}$ and Vishwambhar Jadhav ${ }^{2^{*}}$ \\ ${ }^{1}$ Department of Education, University of Mumbai, Maharashtra, India \\ ${ }^{2}$ Department of Physical Education, University of Mumbai, Maharashtra, India \\ "Corresponding author: vishu1874@gmail.com
}

Received: $14-03-2020$

Revised: $12-06-2020$

Accepted: 27-07-2020

\begin{abstract}
No one in this entire world, including India had experienced a situation like lockdown which came up suddenly and took people unawares. Educational institutions too were badly affected by this. The researchers being teachers themselves were curious to know whether students undertake any physical activities during lockdown and if so, what type of activities were undertaken. For this purpose, an online exploratory survey was conducted on 403 college students using available sampling technique. It was found that (i) A large majority of the students do not have medical problems, (ii) A large majority of the students are either happy or indifferent towards lockdown, (iii) A large majority of the students do some kind of exercise during lockdown, (iv) Majority of the students do not do Yogasana, (v) About onethird of the students do some form of Pranayama such as Kapalbhati, Anulom-Vilom, Ujjayani, Sheetali and Sheetkari, (vi) Only one-eighth of the students work on treadmill and one-third of the students do weight-training during lockdown, (vii) About one fourth of students do meditation during lockdown, (viii) About half the students in the survey state that they have gained weight or may have gained weight during lockdown and (ix) In other words, it may be concluded that relatively fewer students are conscious about benefits of physical activities. Colleges need to prepare and motivate students for maintaining health through curriculum and co-curricular activities on a regular basis.
\end{abstract}

Keywords: Physical Activities, College Students, Lockdown

During the current lockdown on account of the COVID-19 pandemic, students who were actually preparing for their examinations suddenly found themselves completely home-bound with all their lectures were getting delivered online. Some also may be anxious and stressed due to continuous, loud announcements of TV channels about the occurrence of COVID-19 in India and other countries in the world. In order to cope with such an unprecedented or exceptional situation, it is essential to know whether the young students undertook any physical activities within their homes so as to maintain their physical and mental health.

\section{Concept of Physical Activity}

Physical activity is defined as any movement of the body which is produced due to skeletal muscles on account of expending energy. It may involve activities such as walking, gardening, briskly pushing a baby stroller, climbing the stairs, playing cricket or football or dancing. For health benefits, physical activity should be moderate or vigorous intensity. Physical activities can be broadly classified into four types, namely, (a) aerobic, (b) musclestrengthening, (c) bone-strengthening and (d) stretching. Aerobic activity is the type that benefits your heart and lungs the most. Physical activity

How to cite this article: Pandya, S. and Jadhav, V. (2020). Physical Activities of Students During Lockdown: An Exploratory Survey. Educational Quest: An Int. J. Edu. Appl. Soc. Sci., 11(2): 101-106.

Source of Support: None; Conflict of Interest: None (c) $\odot$ 
can also be classified as structured or incidental. Structured physical activity or exercise is planned and purposeful activity undertaken to enhance health and fitness benefits. On the other hand, exercise is a subcategory of planned, structured, and repetitive physical activity and its ultimate or an intermediate objective is to improving or maintaining physical fitness.

In the present study, the researchers have included stretching exercise, Yogasan, Pranayama, Treadmill or Weight Training.

\section{Importance of Physical Activity}

About 60 years back, the initial works of Morris et al. found that the occurrence of coronary heart disease in bus conductors who climbed up and down stairs of double-deck buses collecting tickets and in postal carriers who delivered the mail on foot was lower than that of the comparatively inactive bus drivers or postal office workers who live a sedentary occupational lives. Thereafter, several other researchers have established a strong association between physical activity and health in a many populations. The deleterious effects of physical inactivity are associated with many of the most common chronic diseases and conditions, including heart disease, type 2 diabetes, high blood pressure, obesity, osteoporosis, depression and breast and colorectal cancers.

Statement of the Problem : What are students' physical activities during lockdown?

Methodology of the Study : The study adopted the survey method of the exploratory type wherein an attempt was made to collect first-hand data about students' physical activities during lockdown.

\section{Assessment of Physical Activity}

There are two major types of methods of assessing physical activity, namely, (a) subjective methods and (b) objective methods. Subjective methodologies record individual activities as they occur or to recall previous activities. Objective methodologies use wearable monitors that directly measure one or more bio-signals, such as acceleration, heart rate, or some other indicator of physical activity or energy expenditure. In the present study, the subjective method of recalling previous individual physical activities was adopted.

\section{Tool of the Study}

The data were collected using an online questionnaire consisting of 19 questions. The questions included in the questionnaire focussed on collecting data about students' background information such as their name, name of their college, class in which they are studying, gender, whether they suffered from any medical problems, how have they taken the lockdown, frequency of exercise and type of exercise undertaken. Initially, the questionnaire was developed and a dry run was conducted on 20 students. After a few minor modifications based on the dry run, the questionnaire was finalised.

\section{Sample}

The sample of the study included 403 undergraduate students in the age-group of 17-22 and studying in colleges affiliated to University of Mumbai. The sample included 291 girls and 112 boys from 221 institutions. The sample was selected using available sampling technique since the data were collected online. The sample size was determined using Morgan's table (https://shodhganga.inflibnet.ac.in/ bitstream/10603/154745/20/20_appendix\%203.pdf). According to this table, a sample size of 403 was found to be adequate.

\section{DATA ANALYSIS}

The data were analysed using chi-square technique and graphically.

\section{Medical Problems in Students}

Null Hypothesis : The percentage of students with existence or lack of medical problems is equally distributed.

This null hypothesis was tested using the ChiSquare test. The following results were obtained :

$$
\chi^{2}=160.93, \mathrm{P}<.0001
$$

The Chi-Square is significant $(\mathrm{P}<.0001)$, the null hypothesis was rejected. The percentage of students with existence or lack of medical problems is not equally distributed. A very large majority of students $(93.5 \%)$ do not have medical problems. The following figure shows the percentage of students having medical problems. 


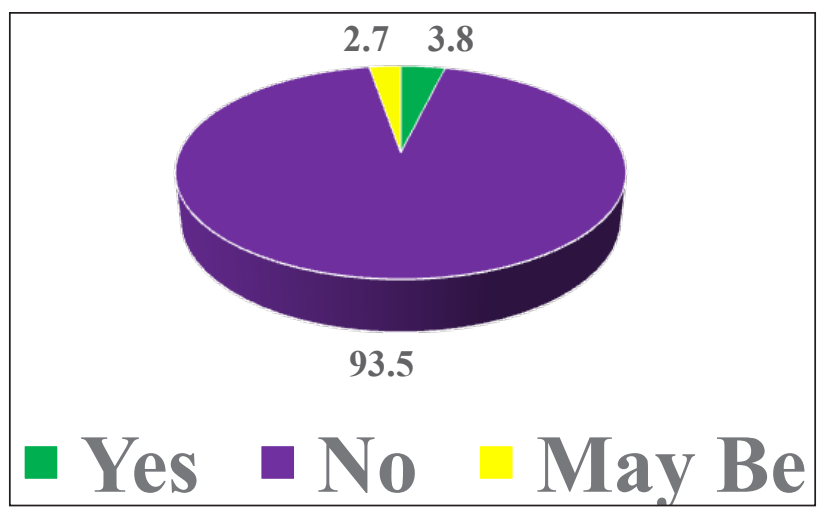

Fig. 1: Medical Problems in Students

\section{Attitude towards Facing the Lockdown}

Null Hypothesis: The percentage of students who have taken the lockdown positively, negatively or neutrally is equally distributed.

This null hypothesis was tested using the ChiSquare test. The following results were obtained:

$$
\chi^{2}=25.55, \mathrm{P}<.0001 .
$$

The Chi-Square is significant $(P<.0001)$, the null hypothesis was rejected. The percentage of students who have taken the lockdown positively, negatively or neutrally is not equally distributed. Many students have taken the lockdown positively (50.4\%) while a few others have taken it neutrally (39.2\%). The following figure shows the percentage of students who have taken the lockdown positively, negatively or neutrally.

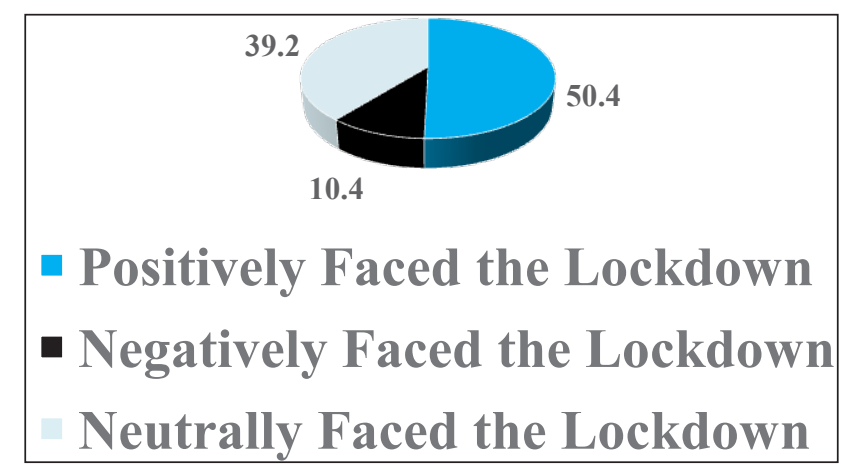

Fig. 2: Attituude Towards Facing the Lockdown

\section{Students' Feelings During Lockdown}

Null Hypothesis: The percentage of students with different feelings during lockdown is equally distributed.

This null hypothesis was tested using the ChiSquare test. The following results were obtained :

$$
\chi^{2}=11.57, \mathrm{P}=0.0031 .
$$

The Chi-Square is significant $(\mathrm{P}=0.0031)$, the null hypothesis was rejected. The percentage of students with different feelings differs significantly. It is pertinent to observe that majority of the students are either happy or indifferent towards lockdown. The following figure shows the percentage of students with different feelings towards lockdown.

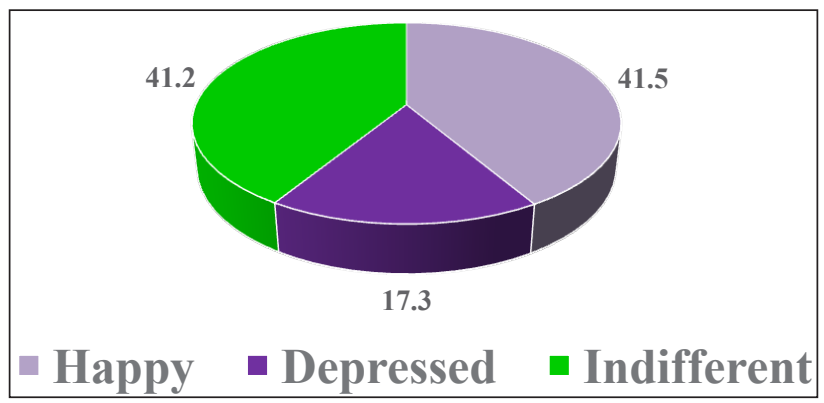

Fig. 3: Percentage of Students with Different Feelings Towards Lockdown

\section{Frequency of Exercise During Lockdown}

Null Hypothesis: The percentage of students with different frequency of exercise during lockdown is equally distributed.

This null hypothesis was tested using the ChiSquare test. The following results were obtained :

$$
\chi^{2}=0.78, \mathrm{P}=0.9411
$$

The Chi-Square is not significant $(\mathrm{P}=0.9411)$, the null hypothesis was accepted. The percentage of students with different frequencies of exercise a week do not differ significantly.

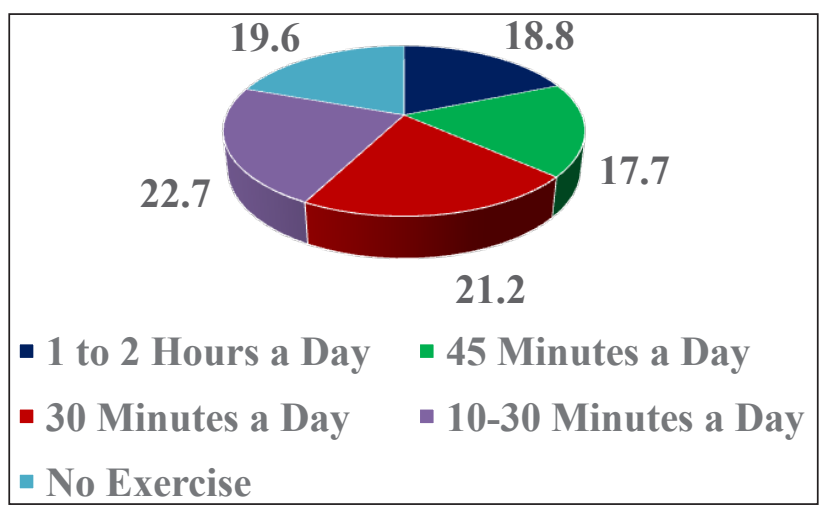

Fig. 4: Frequency of Exercise

It is pertinent to observe that only $19.6 \%$ of the students do not exercise at all. On the other hand, $80.4 \%$ of the students have undertaken at least some 
amount of exercise. The following figure shows the percentage of students who have done exercise in different levels during lockdown.

\section{Performance of Yogasana During Lockdown}

Null Hypothesis : The percentage of students with performance of Yogasana during lockdown is equally distributed.

This null hypothesis was tested using the ChiSquare test. The following results were obtained :

$$
\chi^{2}=3.32, \mathrm{P}=0.0684 .
$$

The Chi-Square is significant $(\mathrm{P}=0.0684)$, the null hypothesis was rejected. The percentage of students performing Yogasana differs significantly. It is pertinent to observe that only $40.4 \%$ of the students perform Yogasana. The following table shows the percentage of students who have done Yogasana during lockdown. Students further state that they do Surya-namaskar, Mandukasan, Vakrasan, Bhujangasan, Shirsasan, Pashchimottasan, Tadasan, Naukasan and Setubandhasan.

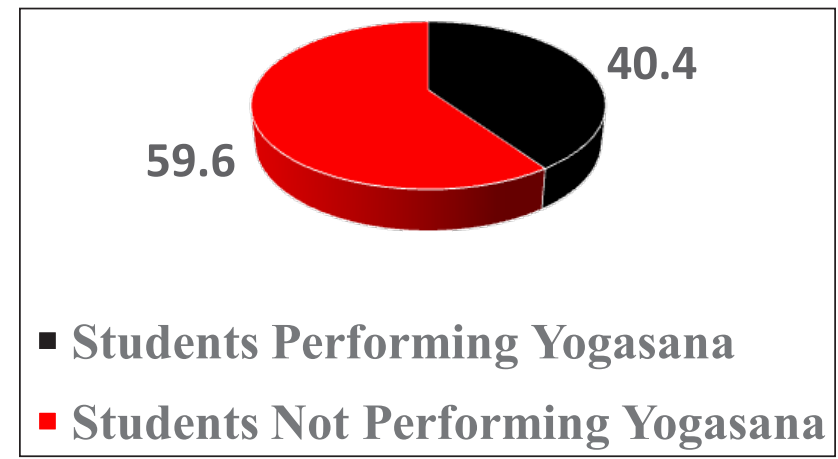

Fig. 5: Percentage of Stuents Doing Yogasana

\section{Performance of Pranayama During Lockdown}

Null Hypothesis: The percentage of students with performance of Pranayama during lockdown is equally distributed.

This null hypothesis was tested using the ChiSquare test. The following results were obtained :

$$
\chi^{2}=11.84, \mathrm{P}=0.0006
$$

The Chi-Square is significant $(\mathrm{P}=0.0006)$, the null hypothesis was rejected. The percentage of students performing Pranayama differs significantly. It is pertinent to observe that only $32.3 \%$ of the students perform Pranayama. The following table shows the percentage of students who have done Pranayama during lockdown. Students further stated that they do Kapalbhati, Anulom-Vilom, Ujjayani, Sheetali and Sheetkari.

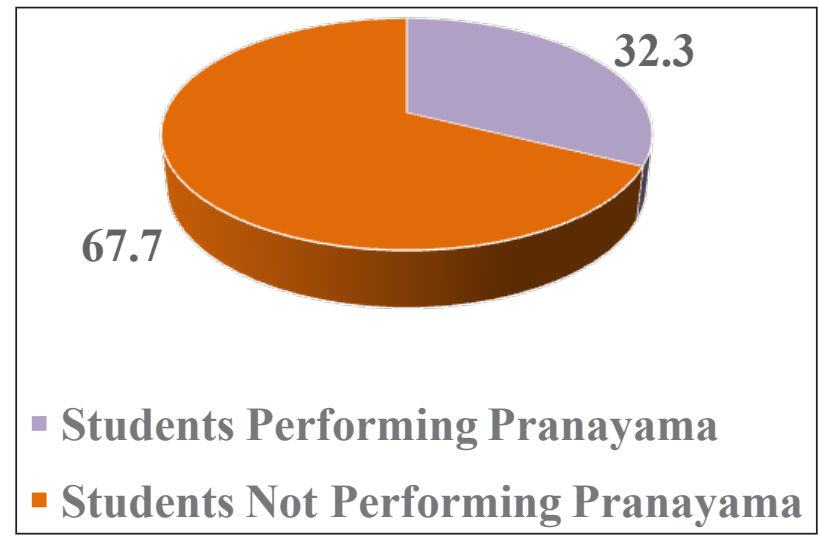

Fig. 6: Percentage of Stuents Doing Pranayama

\section{Performance of Exercise on Treadmill During Lockdown}

Null Hypothesis: The percentage of students with exercise on treadmill during lockdown is equally distributed.

This null hypothesis was tested using the ChiSquare test. The following results were obtained:

$$
\chi^{2}=51.84, \mathrm{P}<0.0001 \text {. }
$$

The Chi-Square is significant $(\mathrm{P}<0.0001)$, the null hypothesis was rejected. The percentage of students performing exercise on treadmill differs significantly. It is pertinent to observe that only $13.5 \%$ of the students perform exercise on treadmill. The following table shows the percentage of students who have done exercise on treadmill during lockdown.

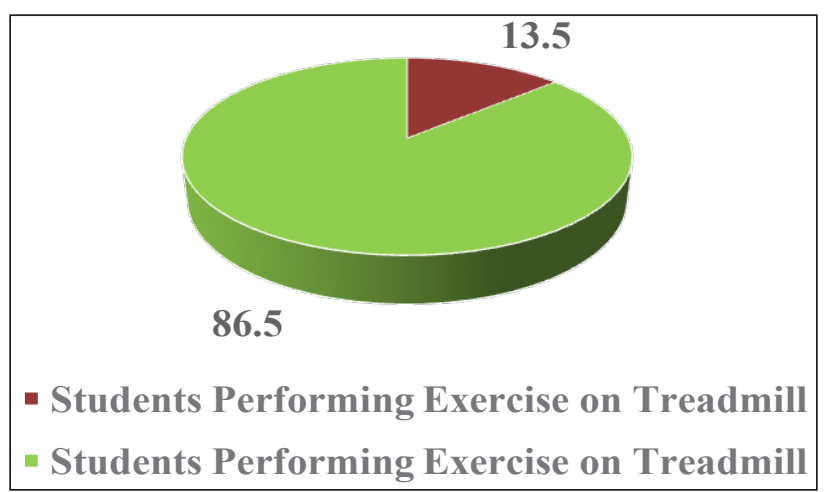

Fig. 7: Percentage of Students Doing Exercise on Treadmill 


\section{Performance of Weight Training During Lockdown}

Null Hypothesis: The percentage of students doing weight training during lockdown is equally distributed.

This null hypothesis was tested using the ChiSquare test. The following results were obtained:

$$
\chi^{2}=11.84, \mathrm{P}=0.0006
$$

The Chi-Square is significant $(\mathrm{P}=0.0006)$, the null hypothesis was rejected. The percentage of students doing weight training differs significantly. It is pertinent to observe that only $13.5 \%$ of the students are doing weight training during lockdown. The following table shows the percentage of students who have done weight training during lockdown.

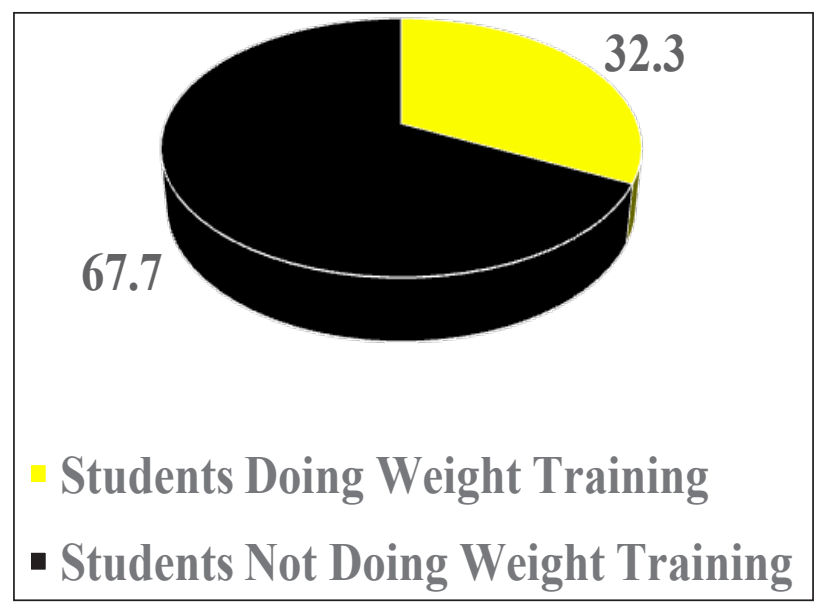

Fig. 8: Percentage of Students Doing Weight Training

\section{Performance of Meditation During Lockdown}

Null Hypothesis: The percentage of students doing meditation during lockdown is equally distributed.

This null hypothesis was tested using the ChiSquare test. The following results were obtained :

$$
\chi^{2}=33.8, \mathrm{P}<0.0001
$$

The Chi-Square is significant $(\mathrm{P}<0.0001)$, the null hypothesis was rejected. The percentage of students doing meditation differs significantly. It is pertinent to observe that a large majority of students either do meditation sometimes or never during lockdown. The following table shows the percentage of students who have done meditation during lockdown.

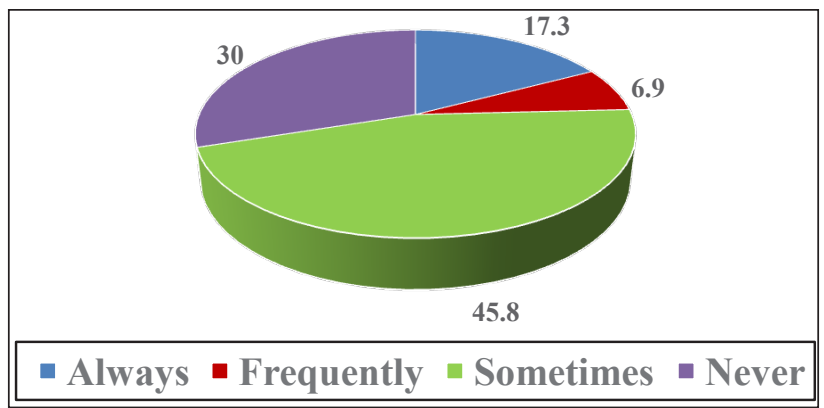

Fig. 9: Percentage of Students Doing Meditation

\section{Performance of Students Gaining Weight During Lockdown}

Null Hypothesis : The percentage of students gaining weight during lockdown is equally distributed.

This null hypothesis was tested using the ChiSquare test. The following results were obtained :

$$
\chi^{2}=4.29, \mathrm{P}=0.1171 \text {. }
$$

The Chi-Square is not significant $(\mathrm{P}=0.1171)$, the null hypothesis was accepted. The percentage of students gaining weight during lockdown does not differ significantly. The following table shows the percentage of students who have gained weight during lockdown.

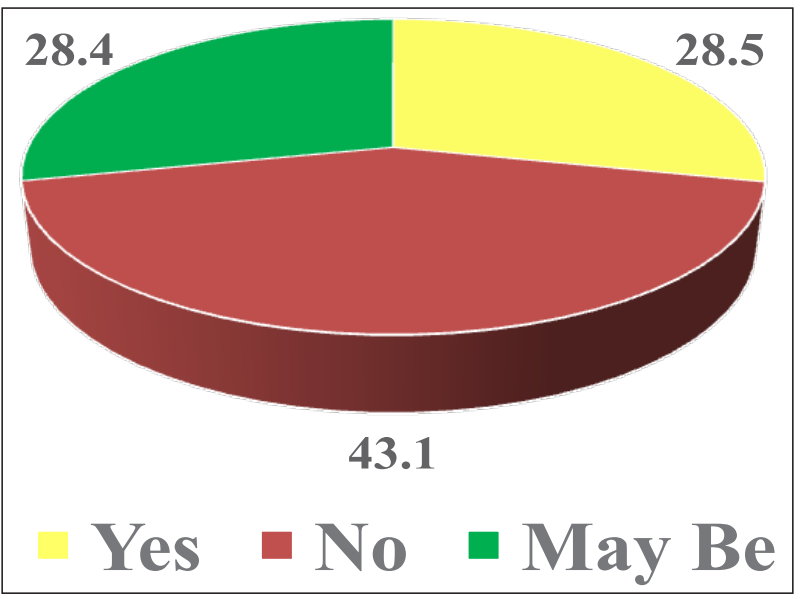

Fig. 10: Percentage of Students Gaining Weight During Lockdown

\section{CONCLUSION}

1. A large majority of the students do not have medical problems.

2. A large majority of the students are either happy or indifferent towards lockdown. 
3. A large majority of the students do some kind of exercise during lockdown.

4. About $40 \%$ of the students do Yogasana such as Surya-namaskar, Mandukasan, Vakrasan, Bhujangasan, Shirsasan, Pashchimottasan, Tadasan, Naukasan and Setubandhasan.

5. About one-third of the students do some form of Pranayama such as Kapalbhati, AnulomVilom, Ujjayani, Sheetali and Sheetkari.

6. Only one-eighth of the students work on treadmill and one-third of the students do weight-training during lockdown. This percentage is relatively low perhaps because not everyone can afford such equipment at home.

7. About one fourth of students do meditation during lockdown.

8. About half the students in the survey state that they have gained weight or may have gained weight during lockdown.

9. In other words, it may be concluded that relatively fewer students are conscious about benefits of physical activities.

Implications of the Study : Colleges need to prepare and motivate students for maintaining health through curriculum and co-curricular activities on a regular basis.

\section{REFERENCES}

Ainsworth, B.E., Richardson, M.T., Jacobs, D.R., Leon, A.S. and Sternfeld, B. 1999. Accuracy of recall of occupational physical activity by questionnaire. Journal of Clinical Epidemiol., pp. 219-227.

Chenoweth, D. and Leutzinger, J. 2006. The economic cost of physical inactivity and excess weight gain in American adults. Journal of Physical Activities and Health, 3: 148-163.

Fletcher, G.F., Balady, G., Blair, S.N., Blumenthal, J., Caspersen, C., Chaitman, B., Epstein, S., Froelicher, E.S., Froelicher, V.F., Pina, I.L. and Pollock, M.L. 1996. Statement on exercise: benefits and recommendations for physical activity programs for all Americans: a statement for health professionals by the Committee on Exercise and Cardiac Rehabilitation of the Council on Clinical Cardiology, American Heart Association. Circulation, 94: 857-862.
Heady, J.A., Morris, J.N., Kagan, A. and Raffle, P.A. 1961. Coronary heart disease in London businessmen: a progress report with particular reference to physique. British Journal Preventive and Social Medcines, 15: 143-153.

https://shodhganga.inflibnet.ac.in/bitstream/ 10603/154745/20/20_appendix\%203.pdf

Jacobs, D.R., Ainsworth, B.E., Hartman, T.J. and Leon, A.S. 1993. A simultaneous evaluation of 10 commonly used physical activity questionnaires. Medicine and Science in Sports and Exercise, 25: 81-91.

Lee, I.M., Shiroma, E.J., Lobelo, F., Puska, P., Blair, S.N., and Katzmarzyk, P.T. 2012. Physical Activity Series Working Group. Effect of physical inactivity on major non-communicable diseases worldwide: an analysis of burden of disease and life expectancy. Lancet, 380: 219-229.

Morris J.N., Heady, J.A., Raffle, P.A., Roberts, C.G. and Parks, J.W. 1953. Coronary heart-disease and physical activity of work. Lancet, 265: 1111-1120.

National Center for Chronic Disease Prevention and Health Promotion. Chronic Diseases: The Power to Prevent, the Call to Control: At a Glance, 2009. Atlanta, GA: Centers for Disease Control and Prevention; 2009. Report No. CS123157.

Strath, S.J., Bassett, D.R. and Swartz, A.M. 2004. Comparison of the College Alumnus Questionnaire physical activity index with objective monitoring. Ann. Epidemiol., 14: 409-415.

US Department of Health and Human Services. Physical Activity and Health: A Report of the Surgeon General. Atlanta, GA: US Department of Health and Human Services, Centers for Disease Control and Prevention, National Center for Chronic Disease Prevention and Health Promotion; 1996.

US Department of Health and Human Services. Physical Activity Guidelines Advisory Committee Report, 2008. Washington, DC: US Department of Health and Human Services; 2008. http://www.health.gov/ paguidelines/report/. Accessed July 28, 2020.

Wareham, N.J. and Rennie, K.L. 1998. The assessment of physical activity in individuals and populations: why try to be more precise about how physical activity is assessed? International Journal of Obesity Related Metabolic Disorders, 22(suppl 2): S30-S38. 